\title{
Unilateral Absolute Blindness: Prevalence, Causes and Profile in A Tertiary Ophthalmic Out-Patient Nigerian Population
}

\author{
Stella Ngozi Onwubiko*, Nkiru Zuadae Nwachukwu and Boniface Ikenna Eze \\ Department of Ophthalmology, University of Nigeria Teaching Hospital, Nigeria
}

Submission: January 20, 2020; Published: May 26, 2020

*Corresponding author: Stella Ngozi Onwubiko, Department of Ophthalmology, University of Nigeria Teaching Hospital, PMB 01129, Ituku-Ozalla, Enugu, Nigeria

\begin{abstract} Nigeria.

Objective: To determine the prevalence, causes and profile of unilateral absolute blindness in University of Nigeria Teaching Hospital Enugu,

Methods: This was a cross-sectional, descriptive, hospital-based survey involving 119 participants with unilateral absolute blindness (no perception of light) out of the 14,439 patients, who attended the ophthalmic clinic from $1^{\text {st }}$ December 2009 to $28^{\text {th }}$ February 2011. Information on their socio-demographic characteristics and clinical ophthalmic profile were collected using a close-ended, interviewer-administered questionnaire. Causes of the absolute blindness were ascertained following ophthalmic evaluation. Data was analysed using SPSS 21

Results: The participants comprised of 64 males and 55 females with a mean age of $51.52 \pm 22.16$ SD years, and age range 2-93. They had at least primary school education, were predominantly farmers and lived in rural areas. The prevalence of unilateral absolute blindness was $0.82 \%$, ( $0.44 \%$ in males, and $0.38 \%$ in females). Glaucoma, $42(35 \%)$ and trauma $23(19.3 \%)$ were the commonest causes of absolute blindness. The majority of the participants had absolute blindness for more than three months (84.1\%) with diseased fellow eyes (66.4\%). Causes of disease in the fellow eyes included glaucoma, cataract, aphakia and refractive error.

Conclusion: The prevalence of unilateral absolute blindness is significant in the study area. These patients are on verge of being bilaterally and irreversibly blind from glaucoma. Interestingly, cataract, aphakia and refractive error are amenable to cost effective treatments. Appropriate public eye health measures to forestall this tragedy, particularly targeting poorly educated farmers in the rural areas are therefore advised.

Keywords: Unilateral Absolute Blindness; Causes; Prevalence
\end{abstract}

\section{Introduction}

Unilateral visual loss has considerable impact on quality of life $[1,2]$. Though the burden is worse with bilateral loss [2], it should be noted that diseases like glaucoma and age-related macular degeneration (AMD), common causes of irreversible blindness worldwide are usually asymmetrical. Timely intervention is thus sight-saving. Few studies have investigated the causes of unilateral visual loss with varying definitions of blindness and the consequent variable prevalence, ranging from 1-7.8\% [35] Amblyopia, AMD, diabetic retinopathy (DR) were common causes among an elderly Danish population [3]. Corneal diseases and cataract were reported in urban India [4] while in Oman [5], phthisis bulbi, and glaucoma were the main causes of unilateral loss. To best knowledge of the researchers, studies exploring the prevalence, causes and profile of absolute blindness have not been done within the study area and the importance of such data in eye health policy planning where access to eye care services is an issue cannot be over emphasised. Its relevance in line with the global initiative of elimination of avoidable blindness, Vision 2020 is quite obvious. Hence, the decision to embark on this study.

\section{Methods}

Background: The University of Nigeria Teaching Hospital (UNTH), Enugu, is one of the first generation tertiary health facilities in Nigeria, established in 1971. It is located in Enugu state, within the tropical rainforest climatic zone, and the southeast geopolitical zone of Nigeria. UNTH provides tertiary health care services in all major medical and surgical specialties, undertakes undergraduate and postgraduate medical training, and conducts research. UNTH's Ophthalmology Department is staffed by consultant and trainee ophthalmologists, optometrists, 
ophthalmic technician, and ophthalmic nurses. It provides inpatient and outpatient promotive, preventive, curative and rehabilitative eye care services to the inhabitants of Enugu state, the other four states in south-east geopolitical zone, and beyond.

Eligibility: Ophthalmic patients with visual acuity of no perception of light (NPL) in one eye who attended the eye clinic during the study period and voluntarily gave an informed consent to participation.

Ethics: Prior to the start of the study, ethics clearance compliant with 1964 Helsinki Declaration, was obtained from University of Nigeria Teaching Hospital's Medical and Health Research Ethics Committee (Institutional Review Board).

Study Period: The study was conducted in $1^{\text {st }}$ December 2009- $28^{\text {th }}$ February 2011.

Study Design: This was a cross-sectional, descriptive, hospital-based survey involving 119 participants with NPL out of the 14,439 patients, who attended the ophthalmic clinic during the study period. Information on their socio-demographic characteristics and clinical ophthalmic profile were collected using a close-ended, interviewer-administered questionnaire. Causes of the absolute blindness were ascertained following ophthalmic evaluation by the Researchers.

\section{Sample size \& Sampling:}

Study instrument: This was a pre-tested, 22-item questionnaire comprising two sections. Firstly, the socio demographic information, place of residence and its distance to the nearest eye care facility were sought. Secondly, the clinic ophthalmic profile of the affected eyes and the fellow eyes were inquired.

Study definition: Absolute blindness means a visual acuity of no perception of light.

Data management: Data were cleaned, edited, coded and analysed using the Statistical Package for Social Sciences (SPSS) software for windows, version 21.0 (SPSS Inc, Chicago, Illinois, USA). Data were subsequently categorised by socio-demographic variables and subjected to descriptive statistical evaluation to yield frequencies, percentages, and proportions.

\section{Results}

The participants comprised of 64 males and 55 females with a mean age of $51.52 \pm 22.16$ SD years, (age range 2-93), male 51.28 \pm 22.99 SD years, (3 to 93 ), female $51.80 \pm 21.36$ SD years $(2-89$ ). More than $60 \%$ were aged 60 years and above. The age and sex distribution is as shown in table 1 . The participants had at least primary school education, were predominantly farmers and live in rural areas. Their socio-economic characteristics are shown in table 2. A total of 14,439 patients (males 6,607, females 7,832) were seen during the study period. Out of this, 119 had absolute blindness with a prevalence of $0.82 \%,(0.44 \%$ male, and $0.38 \%$ females). Glaucoma, 42 (35\%) and trauma 23(19.3\%) were the commonest cause of absolute blindness. Other causes are as shown in table 3 . The majority of the participants had absolute blindness for more than three months (84.1\%) with diseased fellow eyes (66.4\%). The participants' clinical profile is as shown in table 4. Significant causes of disease in the fellow eyes were glaucoma, cataract, aphasia and refractive error.

Table 1: Age and sex distribution.

\begin{tabular}{|c|c|c|c|}
\hline \multirow{2}{*}{ Age (Years) } & \multicolumn{2}{|c|}{ Sex } & \multirow{2}{*}{ N(\%), n=119 } \\
\cline { 2 - 4 } & Male & Female & \\
\hline $1-10$ & 4 & 3 & $7(5.9)$ \\
\hline $11-20$ & 2 & 5 & $7(5.9)$ \\
\hline $21-30$ & 12 & 4 & $16(13.4)$ \\
\hline 3 & 4 & 1 & $5(4.2)$ \\
\hline $1-40$ & 4 & 12 & $11(9.2)$ \\
\hline $41-50$ & 12 & 7 & $26(21.8)$ \\
\hline $61-70$ & 12 & 12 & $24(20.20)$ \\
\hline $71-80$ & 11 & 8 & $19(16)$ \\
\hline $81-90$ & 3 & 1 & $4(3.4)$ \\
\hline $91-100$ & $64(53.8)$ & $55(46.2)$ & $119(100.0)$ \\
\hline Total (\%) & & & \\
\hline
\end{tabular}

Table 2: Socio-economic distribution.

\begin{tabular}{|c|c|}
\hline Characteristic & $N(\%), n=119$ \\
\hline \multicolumn{2}{|c|}{ Educational status } \\
\hline None & $35(29.4)$ \\
\hline Primary & $37(31.1)$ \\
\hline Secondary & $21(17.6)$ \\
\hline Tertiary & $26(21.8)$ \\
\hline \multicolumn{2}{|c|}{ Occupation } \\
\hline Civil service & $10(8.4)$ \\
\hline Trading & $14(11.8)$ \\
\hline Farming & $30(25.2)$ \\
\hline Artisan & $5(4.2)$ \\
\hline Unemployed/retired & $4(3.4)$ \\
\hline Others & $56(47.1)$ \\
\hline \multicolumn{2}{|c|}{ Marital status } \\
\hline Single & $29(24.4)$ \\
\hline Married & $60(50.4)$ \\
\hline Widowed & $23(19.3)$ \\
\hline Divorced/separated & $7(5.9)$ \\
\hline \multicolumn{2}{|c|}{ Location of Residence } \\
\hline Urban & $56(47.1)$ \\
\hline Rural & $63(52.9)$ \\
\hline
\end{tabular}


Table 3: Etiologic distribution of absolute blindness.

\begin{tabular}{|c|c|}
\hline Causes & N(\%), $\mathbf{n = 1 1 9}$ \\
\hline Glaucoma & $42(35)$ \\
\hline Trauma & $23(19.3)$ \\
\hline RD & $7(5.9)$ \\
\hline Pseudophakic bullous keratopathy & $6((5.0)$ \\
\hline Tumor & $6(5.0)$ \\
\hline Complicated cataract & $5(4.2)$ \\
\hline Toxic optic neuropathy & $4(3.4)$ \\
\hline Squamous cell CA conjunctiva & $4(3.4)$ \\
\hline Retinoblastoma & $3(2.5)$ \\
\hline Post-opt endopthalmitis & $3(2.5)$ \\
\hline DR & $2(1.7)$ \\
\hline Optic atrophy & $2(1.7)$ \\
\hline Pan-ophthalmitis & $2(1.7)$ \\
\hline Panuveitis & $2(1.7)$ \\
\hline Pathological myopia & $2(1.7)$ \\
\hline CRVO + VH & $2(1.7)$ \\
\hline Cortical VI & $1(0.8)$ \\
\hline Total & $119(100.0)$ \\
\hline
\end{tabular}

Table 4: Participants' clinical characteristics.

\begin{tabular}{|c|c|}
\hline Characteristic & $N(\%), n=119$ \\
\hline \multicolumn{2}{|c|}{ Laterality of absolute blindness } \\
\hline $\mathrm{RE}$ & $57(47.9)$ \\
\hline LE & $54(45.4)$ \\
\hline $\mathrm{BE}$ & $8(6.7)$ \\
\hline \multicolumn{2}{|c|}{ Associated pain in the blind eye/s } \\
\hline Yes & $50(42)$ \\
\hline No & $69(58)$ \\
\hline \multicolumn{2}{|c|}{ Duration of ocular illness that lead to blindness } \\
\hline$\leq 3$ months & $19(16)$ \\
\hline$>3$ months & $100(84.1)$ \\
\hline \multicolumn{2}{|c|}{ Time to initial presentation for eye care } \\
\hline$\leq 3$ months & $45(37.8)$ \\
\hline$>3$ months & $74(62.2)$ \\
\hline \multicolumn{2}{|c|}{ Type of eye care sought } \\
\hline Orthodox & $106(89.1)$ \\
\hline Unorthodox & $4(3.4)$ \\
\hline Both & $9(7.6)$ \\
\hline \multicolumn{2}{|c|}{ Status of fellow eye in mono-ocular blindness } \\
\hline Normal & $40(33.6)$ \\
\hline Diseased & $79(66.4)$ \\
\hline
\end{tabular}

\section{Discussion}

The participants in this hospital-based survey comprised of 64 males and 55 females with a mean age of $51.52 \pm 22.16$ SD years, and a range of 2-93 years. More than $60 \%$ were aged 60 years and above. This demographic profile and study setting are similar to the Oman survey [5] though it had more females than males but contrasts with the population-based south Indian survey [6] with a mean age of 27.4 years and the Danish [3] which investigated only the elderly, (60-80 years). This implies that comparison of the findings of this study can be made directly with the Oman [5] but with the other studies [3,6], it should be made with caution. In this study, the prevalence of unilateral absolute blindness was $0.82 \%$. This compares well with the $1 \%$ prevalence reported in Oman [5] but contrasts with the 3.38\% in the Danish [3] population, $7.3 \%$ in the Blue Mountain study [1], 3.8\% in an urban Indian [4] and 7.8\% in a rural Indian [6] studies. The varying definitions of blindness in these studies and the study settings may explain this difference. The Oman [5] survey as well as the present study defined blindness as no perception of light, while others $[1,3,4,6]$ were based on a variable visual acuity of $\leq 3 / 30$ to $<6 / 18$. Future researches in this area in various locations should be designed based on a standardized protocol to allow for a more robust comparison.

Glaucoma, (35\%) and trauma (19.3\%) were the commonest causes of absolute blindness in this study. This is comparable with the Oman study [5] which documented glaucoma and phthisis bulbi, a sequel of infection and trauma as the common causes of nil perception of light. In contrast, AMD and DR were reported in Denmark [3], retinal diseases in Texas [7] and corneal diseases in India [4]. Glaucoma is still a tragedy in developing countries, where late presentation and compliance to medications are major issues as well as cost, fake substandard drugs and resort to traditional / alternative medicines. It is not surprising that it was found to be a common cause of absolute blindness in this study and in Oman [5]. Glaucoma may be more common in the study area than previously thought. More researches investigating its magnitude and burden should be carried out for an effective and efficient eye care planning.

In the diseased fellow eyes of $66.4 \%$ of the participants, glaucoma was also found to a major cause in this study and in Oman [5]. Cataract, aphakia and refractive error were other significant causes of disease in the fellow eyes. The Oman study [5] also documented similar findings. These causes particularly cataract, aphakia and refractive errors are amenable to costeffective corrections. Therefore, appropriate measures to combat this menace should be put in place. Until the fight against glaucoma is intensified as much as that of cataract and refractive errors in developing countries, realising the aim of Vision 2020, the global initiative for elimination of avoidable blindness remains a mirage. 


\section{Conclusion}

The prevalence of unilateral absolute blindness is significant in the study area. These patients are on verge of being bilaterally and irreversibly blind from glaucoma. Interestingly, cataract, aphakia and refractive error are amenable to cost effective treatments. Appropriate public eye health measures to forestall this tragedy, particularly targeting poorly educated farmers in the rural areas are therefore advised.

\section{References}

1. Chia EM, Mitchell P, Rochtchina E, Foran S, Wang JJ (2003) Unilateral visual impairment and health related quality of life: the Blue Mountains Eye Study. Br J Ophthalmol 87: 392-395.

2. Vu HTV, Keeffe JE, McCarty CA, Taylor HR (2005) Impact of unilateral and bilateral vision loss on quality of life. Br J Ophthalmol 89(3): 360 363.

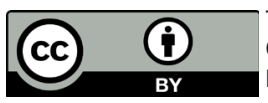

This work is licensed under Creative Commons Attribution 4.0 License

DOI: 10.19080/JOJO.2020.08.555737
3. Buch H, Vinding T, La Cour M, Nielsen NV (2001) The prevalence and causes of bilateral and unilateral blindness in an elderly urban Danish population. The Copenhagen City Eye Study. Acta Ophthalmol Scand 79(5): 441-449.

4. Dandona L, Dandona R, Srinivas M, Mandal P, McCarty CA (2000) Unilateral visual impairment in an urban population in Southern India. Indian J Ophthalmol 48: 59-64.

5. Bansal RK, Khandekar R, Nagendra P,Kurup P (2007) Magnitude and causes of unilateral absolute blindness in a region of Oman: A hospitalbased study. Eur J Ophthalmol 17(3): 418-423.

6. Marmamula S, Khanna RC, Rao GN (2016) Unilateral visual impairment in rural south India-Andhra Pradesh Eye Disease Study (APEDS). Int J Ophthalmol 9(5): 763-767.

7. Apte RS, Scheufele TA, Blomquist PH (2001) Etiology of blindness in an urban community hospital setting. Ophthalmology; 108: 693-696.

Your next submission with Juniper Publishers
will reach you the below assets
- Quality Editorial service
- Swift Peer Review
- Reprints availability
- E-prints Service
- Manuscript Podcast for convenient understanding
- Global attainment for your research
- Manuscript accessibility in different formats
( Pdf, E-pub, Full Text, Audio)
- Unceasing customer service
Track the below URL for one-step submission
https://juniperpublishers.com/online-submission.php

